\title{
Documentality - Or Why Nothing Social Exists Beyond the Text
}

\author{
MAURIZIO FERRARIS, TURIN
}

\section{Introduction}

If April is the most cruel month, what about August? I am stuck in the passport office, it's hot, there's a huge crowd (everybody is as disheartened as me) and, as if that wasn't enough, the take-a-number dispenser is broken. Then the queue is no longer governed by something put down in black and white, but only by memory. And memory of people taking part in such a rite is shaky and it gets often overwhelmed by personal interest, so the queue becomes somewhat problematic. Now, between issuing a passport and the regulation of a queue, there is a connection which is not only de facto, but de jure.

What I'm trying to obtain with the passport is a way of fixing memory, something that can guarantee my identity. Otherwise, I would be forced to travel with a lot of acquaintances and even with some policemen, who would be in charge of safeguarding my rights. And this story would never come to an end. For instance, in a world without documents, money and credit cards would also not exist, and all travelling people should carry with them a huge amount of chattels, like Swift's Lagado's Academics.

This fact points out the key-category of social ontology, which I propose to call documentality. And it has simply nothing to do with a technical way of preserving memory. It entails also major consequences on our personal identity. The fact that being "sans papier" amounts to being devoid of citizenship (and of the associated rights) is extremely revealing as to the significance of documents, namely of those things that we shall regard as objects that record social events.

In this paper I will define the nature of social objects, their rule of constitution, and the role of an ontology of documents.

\section{Social Objects}

Let's start from the beginning. Research projects, books, lessons, relationships, votes, credits, exam certificates, records, academic degrees, students 
and their halls, professors and their chairs, art works and consumer literature, application forms, revolutions, workshops, conferences, firings, unions, parliaments, stock societies, laws, restaurants, money, property, governments, marriages, elections, games, cocktail parties, tribunals, lawyers, wars, humanitarian missions, voting, promises, buying and selling, prosecutors, physicians, perpetrators, medieval soldiers, presidents. What are all these objects made of? And, above all, are they objects? Some philosophers would say they are not objects, because only physical objects exist. Other philosophers would go so far as to say that even physical objects are socially constructed, because they are the results of our theories. Thus, their world would be indeed Prospero's world: We are such stuff / As dreams are made on and our little life / Is rounded with a sleep.

This cannot be the case, though: social objects do indeed exist, the proof is that giving a lecture is different from thinking about giving one. And it is in this context that we can find what an American philosopher, John Searle, in 1995 has called "a huge invisible ontology", the ontology of social objects.

What's it about? Let's start by making some examples of non-social objects: mountains and lakes, trees and atoms exist even if we don't think about them, and they would still exist even if no human being would have ever inhabited Earth. And the same also holds for numbers and theorems. The objects of the first type are physical objects existing in space and time, quite independently from subjects. The objects of the second type are rather ideal objects existing out of space and time, but still independently from subjects (if Pythagoras' theorem would have been discovered by Euclid, we would now know it as "Euclid's Theorem" but it would be, nonetheless, the very same theorem).

So far, so good. But what's the place in this classification for such things as this seminar, or our Congress as a whole? The Congress surely occupies portions of space and time; it has an organizer, participants, etc, and depends on subjects not only in the sense that there is an organizer and there are participants, but also in the (more general) sense that if human beings didn't exist, academies, lunches, conferences and world championships wouldn't exist either. In different terms, I have no difficulty to imagine that this talk could be completely different, but I can by no means imagine this talk taking place in a world inhabited only by, let's say, beavers.

This talk, just like a lot of other things (and if you think about it you soon realize that they are the most important ones in our lives) is a social 
object, that is: an object - this is what I would like to stress - which cannot exist not only without human beings but also without inscriptions. Consider, for instance, the following: would a wedding where all the participants were affected by Alzheimer syndrome be still considered a rightful marriage afterwards?

$\mathrm{X}$ counts as $\mathrm{Y}$ in $\mathrm{C}$

In order to explain the nature of social objects, Searle has formulated the law "X counts as $\mathrm{Y}$ in C", that means that a social object is a higher-order object supervening upon a physical object. In some context $\mathrm{C}$, a man $\mathrm{X}$ is also a prime minister $\mathrm{Y}$ and a piece of paper $\mathrm{X}$ is a banknote $\mathrm{Y}$. So far, so good. But this theory has several counterexamples.

The best illustration of the fact that the identity of a social object such as a state is not warranted by its physical realization is given by the case of Poland. Consider the extent to which Warsaw "moved", eastward and westward, northward and southward, given all the changes that characterized the tormented Polish history. 
The following map represents Warsaw's current position, which is in the east of Poland, given that most of the post-war territorial acquisitions were made at the expense of Germany.

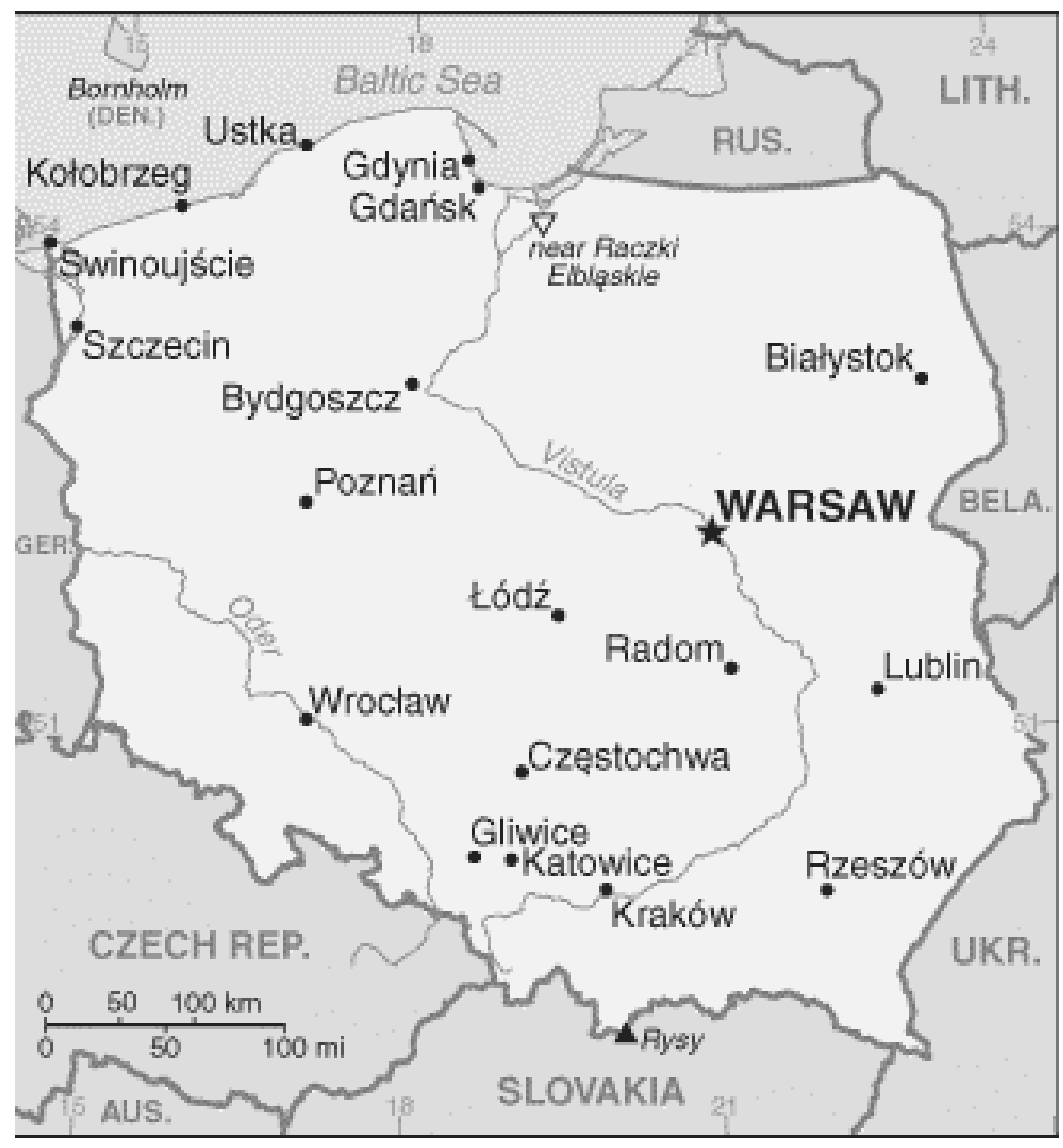


The following map portrays Poland in 1941, under German occupation. Warsaw is located in the west, near the border.

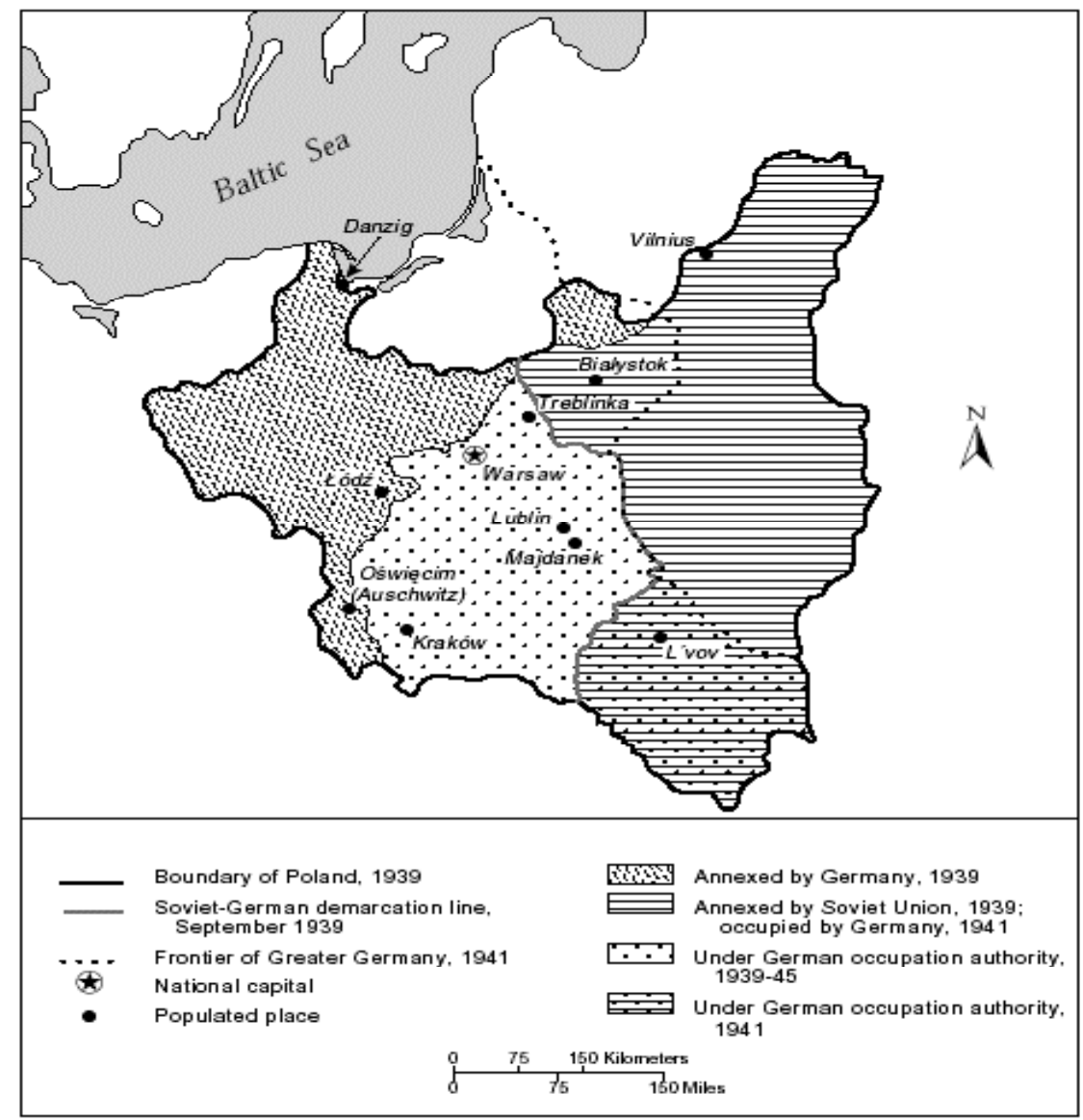


The next picture represents Poland in the Twenties. Warsaw is roughly at the center of a very large territory. This was so because Germany and the Soviet Union, the neighbours of Poland, went through, respectively, a lost war and a revolution.

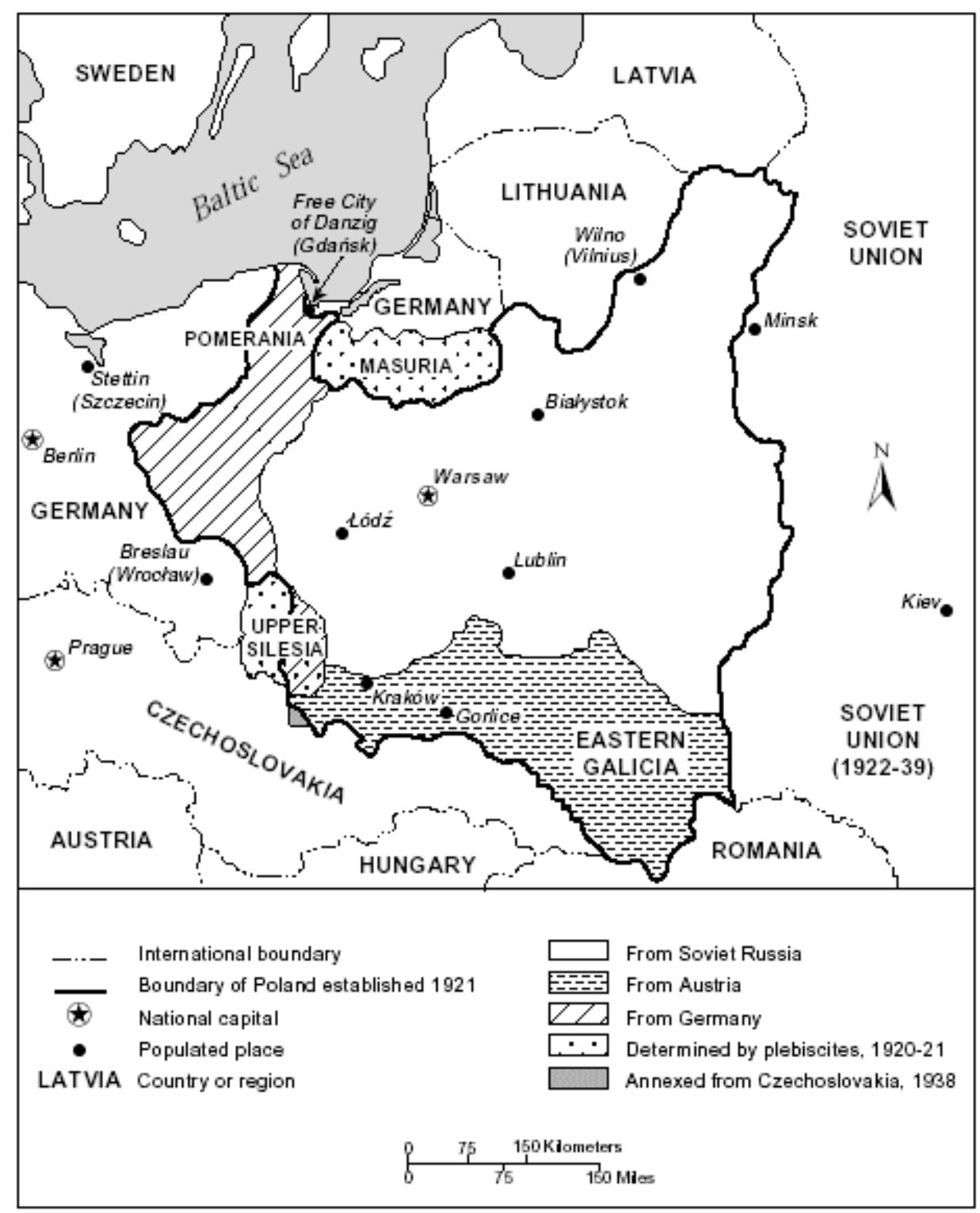


The next picture portrays Poland in Napoleon's times. Warsaw is located near the eastern border.

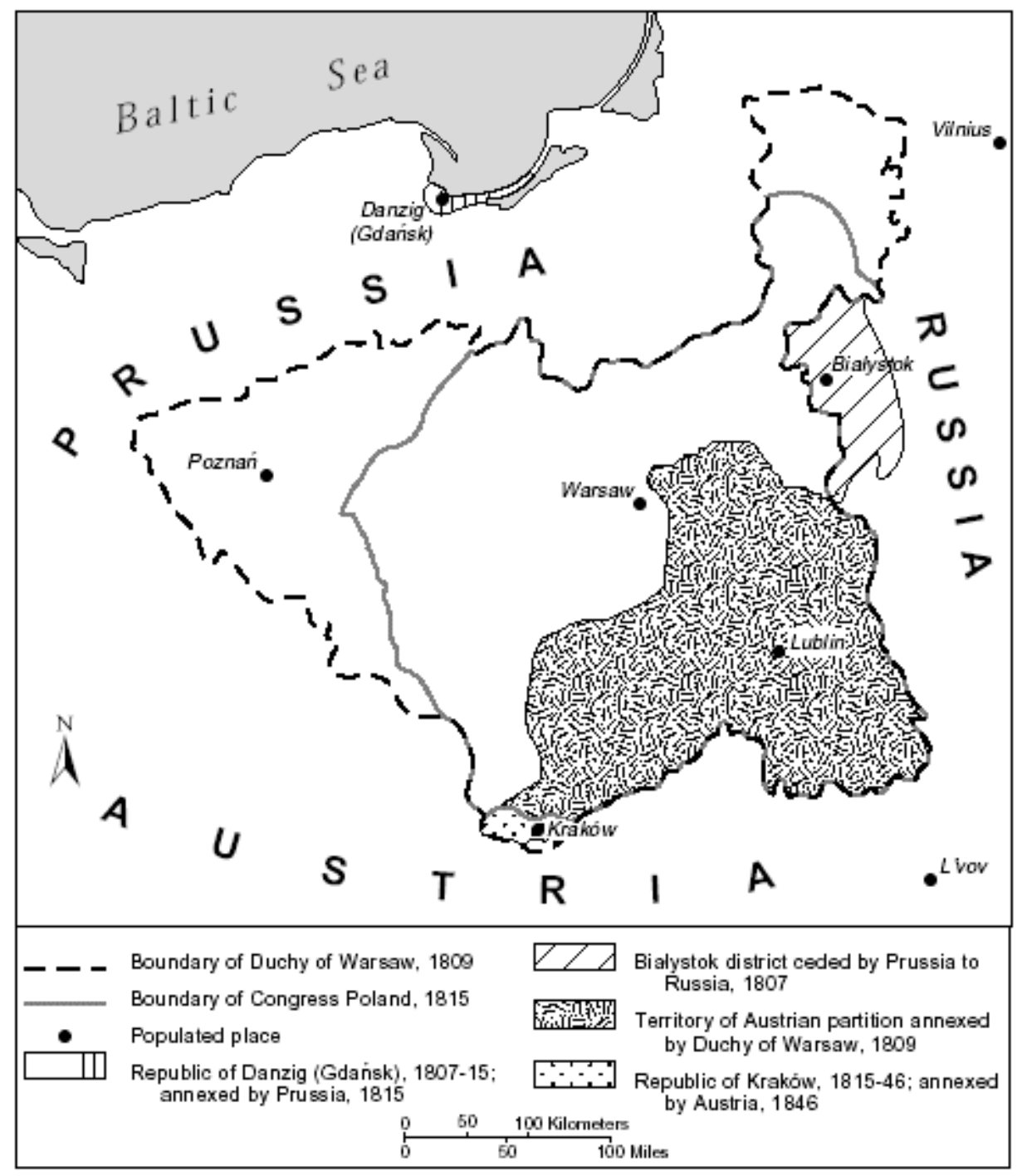


However, it is worth noticing that in 1772 Warsaw was located near the northern border.

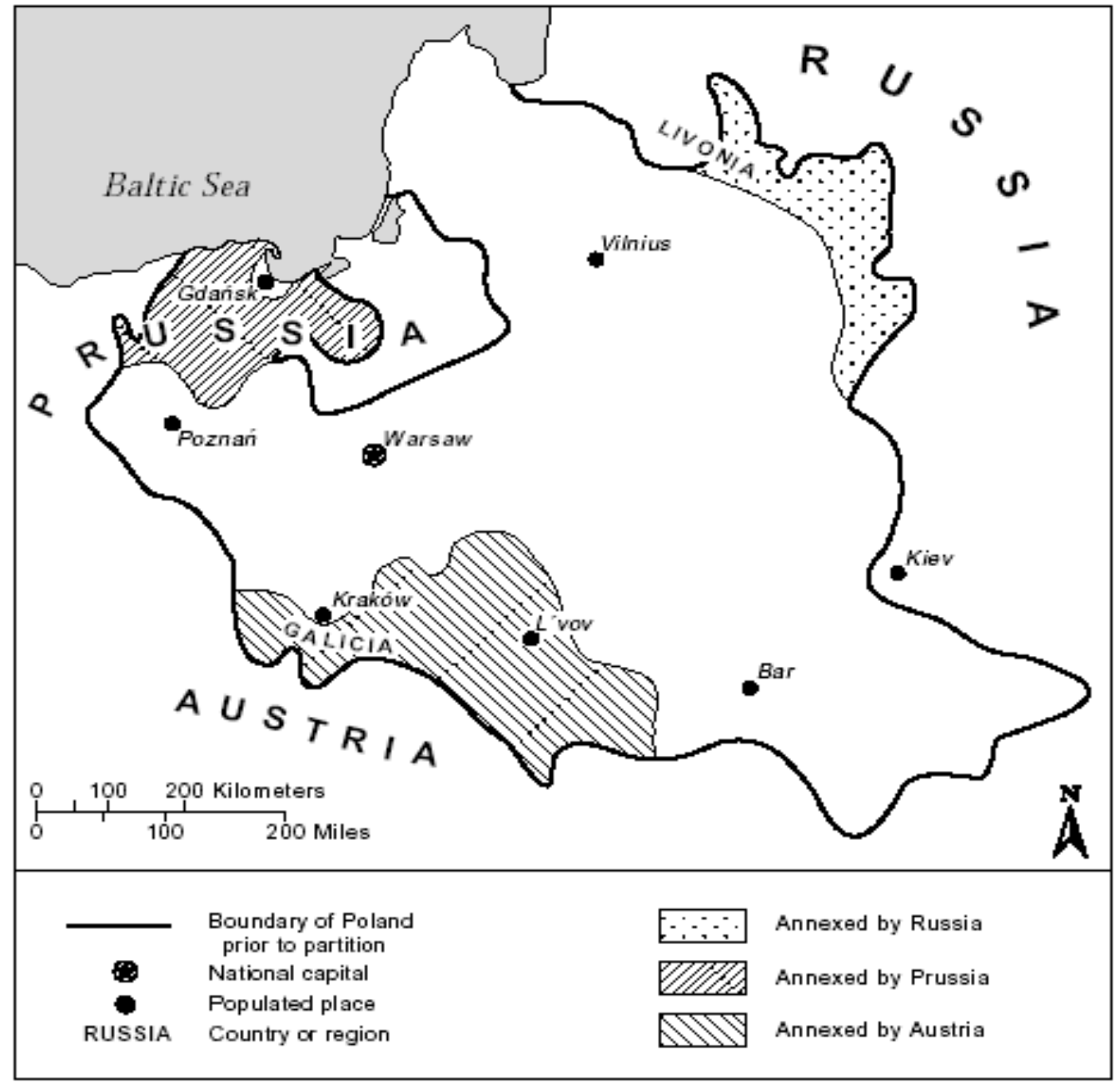


Confusingly enough, moreover, we cannot determine Warsaw's position in 1300 , simply because at that time there was only Poland in existence but not Warsaw.

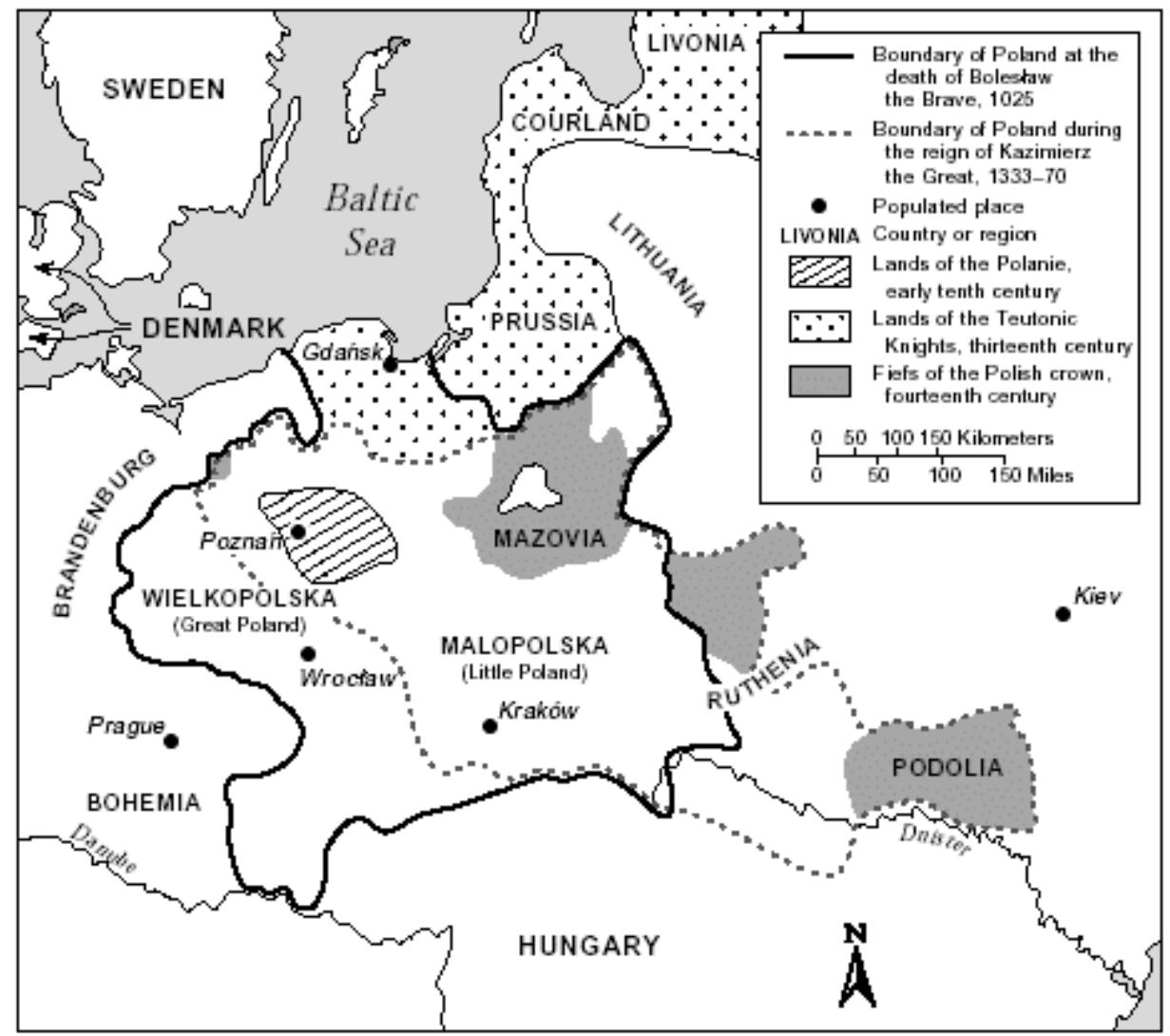


It should be clear then, that the identity of Poland is not founded on its molecules. The identity of Poland is founded on treaties, written records, formal agreements, which all have the interesting feature of having signatures at the bottom of their pages.

Where is the being of Fiat? Consider now the case of a heavy industry such as Fiat, namely a social object whose physical realization, though vast, is made of a smaller number of molecules than the physical counterpart of a State. Fiat in the Thirties consisted in the Lingotto factory, its workers, clerks, and managers, including senator Agnelli, and of course its cars. But is this true?

Of course, this cannot be true, as it wasn't in the case of Poland. The Lingotto factory has recently been turned into a museum, an hotel, a conference building, and, furthermore, Fiat is not its owner anymore; there has been a decreasing number of workers, Agnelli (the old senator, but also his heirs) died or made several bizarre things, but still Fiat continues to exist with many difficulties that however do not affect its identity.

Cars, moreover, constitute Fiat's being only as long as they are not sold to customers. It looks reasonable to explain what happens when one buys a Fiat car by appealing to the notion of contract, which is just a kind of record, having on it the signatures, respectively, of the seller and the buyer. Contracts are at the foundation (together with account books, stocks, communications, letters, faxes, pay envelopes etc.) of the Fiat's identity, which, just like Poland's, does not depend on its physical molecules (all considered, the number of signatures that determines Fiat's identity may well be smaller than the number of signatures that determines Poland's identity).

Where is the being of Telecom? Let us examine now the case of a light industry such as Telecom as it was thirty years ago, when it was named Sip (and before Siptel). Which were the molecules that defined its identity? A certain number of employees, buildings and offices, but characteristically its telephones (which the company owned for a long time) and telephone lines.

Of course, many of us remember that fifteen years ago the Italian market of telephony was freed by Telecom's monopoly on telephone lines, and its telephones were then not the only ones available, to the point that now they are just a tiny minority. Do we have to conclude that Telecom is now something different? In a sense it is, since it is no more the old monopolist company we used to know. But its identity through the successive changes 
from Siptel into Sip and finally into Telecom did not depend on its telephones and wires but - as always - on signatures.

Moral: telephones and telephone lines can disappear or can change ownership, but this does not amount to the end of Telecom. To avoid the latter, it will suffice to take care of the signatures.

Where is the being of Vodafone? This case involves a physical realization with a much smaller number of molecules than the previous ones. In fact, Vodafone has never owned telephones and wires, being a mobile communication company. But then where is the being of Vodafone? Which are the molecules that constitute it?

One may be tempted to answer that Vodafone's being consists in the image of the model Megan Gale, which for several years made Vodafone's advertising in Italy. But of course it cannot be so. Megan Gale represents Vodafone, she is not Vodafone. And she is not Vodafone's property (one can rent a car, but not a person).

Where is, then, the being of Vodafone? Well, the answer is easier than expected: in Sim cards (independently of the kind of support); in registered documents (independently of the kind of support); in its stocks (independently of the kind of support). Three elements that are just different kinds of signatures (the registered SIM card code is the essence of a signature, linking somehow the computer blips in a bank, the genetic code and some traces of ink on a sheet of paper)

Where is the being of Parmalat's Debt? This last case is the hardest one. The molecules involved here are very few, or, better, there seem to be no molecules at all and no physical realization, since we are dealing with something like a "negative entity". Having no molecules at all, then, a debt is infinitely less dense than Poland, Fiat, Telecom and Vodafone. However, when we come to its identity, things are quite different from how they look like at first sight: a debt has roughly the same number of molecules as the previous examples of social objects.

In his Intervista a un suicida [Interview with a suicide] Vittorio Sereni wrote "The shortage was not in the coffers of the city, but in his heart", of a Luino accountant who killed himself because of cash shortage. In Parmalat's times (with all its executives in a "jail meeting", as noticed by the newspaper Il manifesto), the cash shortage is a topical subject. How did they cause the debt?

On the 4th of January 2004, the newspaper La Repubblica reported the following: "According to the original plan, [the documents] had to be buried in a hole, just like a cumbersome dead body, in the flat country just behind 
Parmalat's buildings. But some judges in Milan came into possession of the documents, commanding the first arrests. The documents amounted to three small sheets in which Parmalat's accountants, few hours before the case became public, summarized the balance of the "dump" society named "Bonlat" that was meant to collect all the debts (together with its secrets) caused by Tanzi and his associates. Three small sheets, whose content LaRepubblica will soon reveal."

We must say that the project of hiding the three sheets of paper in a hole is quite imaginative, even if it is partly justified by the idea that some societies may work just like waste disposal sites. However, burning the papers, eating them, tearing them into tiny pieces or even puting them in the closet, they all look like much more practical ways to get rid of three small sheets of paper. But Parmalat's executives wanted too much: another hole, just behind the factory buildings. A hole takes time, and, what's worse, it can easily be discovered as it is clear from the fact that the judges and LaRepubblica entered in possession of the documents very soon. They had just to follow the right traces.

The Enron case is very similar. Among the comments that followed the Enron crack, a financial newspaper suggested a list of things that one could have done with an Enron stock, and the first thing on the list was: "Use it for sanitary disposal and other bathroom activities."

From the previous considerations, then, it seems to follow that Searle is wrong, since even a negative entity requires a physical realization, as in the case of valueless stocks; moreover, what loses its value is not the massive physical counterpart, but the signatures that warrant its exchangeable value, and which - according to my theory - constitute the real essence of such a social object.

\section{Object $=$ Written Act}

I now try to present my theory. Consider the case of debt. There is also in this case, to speak the truth, a physical object, although it is rather a peculiar one: it is something written on a paper or a computer, or simply in the mind of someone. This is the secret of social objects.

I reckon that we do not need massive physical objects (a territory, a human body, a piece of paper or a coin) to obtain a social object: in many cases a few ink molecules, or some neurons, are enough. If we granted this, we would acknowledge that social objects depend on social acts concerning at least two persons-two persons that should be able to remember 
what they do-and an inscription is the only physical thing it takes. The inscription, viz. the trace, is a concept on which Derrida (1967) insisted a lot: without inscriptions of some kind, in the head at least, there would not be society, although, obviously, there may be inscriptions (for instance the notches on Robinson's calendar) without there being a society.

That's why I have proposed in 2005 the law "Object = Written Act": social objects are social acts (such that they involve at least two persons) characterized by the fact of being written: on paper, in a computer file, or simply in people's heads.

This is particularly clear in our age, characterized by an explosion of writing, memories and records. IPod was last Christmas' most popular gift, and this means that the most popular gift was a tabula rasa, the waxen tablet on which it is possible to write and to erase at will, or Freud's Magic Notes, if you prefer. What's new here, however, is the huge amount of space available for storage, and considering that even the smallest newsstand nowadays contains more writings and registrations than the whole Library of Alexandria, that doesn't come as a surprise. Now, given that we are not philosophers for nothing, we move from de facto to de jure considerations.

Twenty years ago, two objects apparently quite different from one another entered in our lives (or, more exactly, in the lives of only a few of us, which I don't know if I should label as "privileged" or rather "unlucky"). These objects were the $P C$ and the mobile phone.

The first one was a monumental device, quite modern but still archaic in certain respects, being made out of heavy metallic parts and with a small screen with tiny- almost unreadable, as a matter of fact - green letters shining against a black background. Moreover, in spite of its imposingness, the PC had less memory than the simplest Gameboy nowadays afloat, and a lot of people (including myself) thought that it was not really needed. "A typewriter is more comfortable" they used to say "and, above all, it's portable, while that cumbersome thing surely isn't!"

Also the second discovery - the mobile phone - was, in those days, of a very remarkable size. At the beginning, it was a sort of walkie-talkie, an object one would have found only in politicians' and top-managers' cars and, I guess, in secret agents' and police chiefs' pockets as well. Probably, this is the reason why I can't clearly remember of these objects in their first appearances (and I think I'm not the only one). Until the end of the past century, it was a tool used only occasionally and especially by people belonging to particular categories, such as the unfaithful husbands, whom the 
mobile phone would enable to have secret conversations first and, later, after the divorce, to replace the house phone.

Two brand new objects, I was saying, and completely different from one another. Two species, so to say, incompatible from an ethological point of view: the first was a sort of typewriter, just a bit more sophisticated, the second was a phone, from which the cable - god knows how had been cut away. The first absolutely didn't communicate in any way. Just think about it: now it could seem unbelievable, but the earlier IBM computers' keyboards - the eighties' ones - used to lack a key. Guess which one? Nothing less than the "@”, the key of e-mail addresses, and this happened simply because at that time there was no e-mail at all. The second neo-object, just like its cabled forerunner, couldn't write a single letter. And, on reflection, it would have struck us as weird to the least if one had bought a telephone for writing. Wouldn't it?

Yes, weird indeed. But now something is happening which is even weirder and right in front of our eyes: the two machines are becoming the same machine. And this is not only a matter of functions (even if, of course, it's true that nowadays we can make low-cost phone calls using computers and that mobile phones have huge and constantly growing amounts of memory, overwhelmingly more powerful than those of the first personal computers) but mostly of physical localization.

In short, the very same object is becoming a computer memory and a mobile phone. And we can be sure that this integration will shortly get total and that the pair computer-mobile phone will eat everything up: cash, credit cards, wallets, ID cards, passports, birth and marriage certificates. This is, no doubt, very practical, but on the other hand loosing your mobile phone now becomes a tragic event: having lost this very one thing you've lost everything, and finding a public phone - at least in Italy, the Kingdom of Mobile Phones - to communicate the fact won't surely be that easy.

So, losing your mobile phone is a little like dying. You become instantly a sans papier, even if in the mobile phone there is no physical paper, but simply a possibility of recording.

\section{Documents}

After the tale, let's go back to theory. With the law Object $=$ Written Act we found the necessary (but not, of course, also sufficient) condition for society: without inscriptions of some sort, even just in the head, there would be no society; on the other hand we can obviously find inscriptions 
without a society, such as the notches on Robinson's calendar. Moreover, the condition I have just mentioned holds specifically for social objects: physical objects, like mountains, or ideal objects, like theorems, exist without inscriptions, but social objects don't (a society without memory is, strictly speaking, unconceivable). It is in this sense that I propose to transform Derrida's thesis (untenable as it is) "There is nothing outside of the text" into "There is nothing social outside of the text". Have a look into your wallet or mobile and you'll understand what I mean.

With all this in place, a theory of documentality can develop in three different directions. The first direction is that of an ontology, which has to answer the question "What is a document?" The second one is that of a technology, whose task is to explain how documents are distributed within a complex society. The last direction is that of a pragmatics (especially legal pragmatics), whose aim is to guarantee an efficient distribution of documents in today's society, characterized as it is by the explosion of writing.

With regard to the first question - what is a document? - what is needed is a full articulation of the law "Object = Written Act". Documentality, in fact, embraces a large domain: from human memory and simple written notes (memos don't have necessarily a social value, but often they acquire one) to international treaties. Moreover, documents can be realized by quite different media (writing on paper, electronic writing, photography...) and they can refer to quite different events and activities (borrowing a book from the library, getting married, giving a name to a child, declaring war...). In the great majority of these realizations, the structure of documentality can be recognized: first of all, a physical support; then an inscription which is, of course, smaller than the physical support but which determines its social value; finally, something idiomatic, typically a signature (and its various variants, such as digital signatures and PIN codes), which guarantee the authenticity of the document.

As to the second question - how is documentality distributed within a complex society? - the queue at the office that I have described doesn't represent an optimal situation, but, luckily, the number of media suitable for the realization of documentality is now increasing: you can pay fines at the tobacco store, pay for parking by mobile phone, buy tickets or pay taxes on-line. In short: if it's true that an advanced society has more needs with regard to documentality, it's true, by the same token, that such a society has more resources, made available by digital supports and technologies (which extend and enhance the law "Object = Written Act") for pay- 
ing bills and taxes, getting certificates, making online purchases and financial transactions.

Let's turn, finally, to the third question. How can we manage documents in a world characterized by the explosion of writing? The problems related to privacy, constantly increasing in advanced societies, are usually interpreted in the light of the recurrent image of a Big Brother, that is, a big watching eye, according to the model of Bentham's Panopticon. On one hand, it's surely true that things like infrared viewers are nowadays widespread as well as cameras that constantly survey every aspect of our lives, in banks, railway-stations, supermarkets, offices and private buildings. On the other hand, however, the power of this big eye would be useless without a registration, which is exactly what transforms a vision in a document. No doubt, the recent debates about phone interceptions are just the tip of an iceberg: the question we are facing here is an important one for democracy, and a complete grasp of the category of documentality is required in order to get a satisfactory answer to it.

\section{Conclusions}

Now that I'm almost done with my speech I would like to conclude with both a memory and a prophecy.

First comes the memory: this future has a very ancient origin, it has been made possible by writing, which, as we have seen, is what has merged computer and mobile phone and what will certainly lead all the future hybridizations which, in turn, will hugely increase our power of storing, registering and acquiring data, in our mobile phones as well as in our memory sticks or iPods, just like it happened in the past, in libraries and pyramids.

Pyramids, libraries, archives, letters ... Here lies the reason why nobody, really nobody except French philosopher Jacques Derrida in his Grammatology (1967), in the middle of the twentieth century, had never even imagined that the great revolutions of the following decades would have been grounded on writing, which guarantees the coming alliance of computer and mobile phone. And it won't take a big deal to verify this claim. Just read at the books from the Fifties: it seemed that writing was deemed to disappear, completely replaced by TV, radio, cinema, what McLuhan labelled as "warm" messages. You could have found not even a trace of email, sms, internet, web, Google, blogs: the spaceship in 2001: A Space Odyssey (which dates from 1968) was equipped with perfectly normal 
typewriters and Hal, the big-brain, served to think and not at all to write. But this is simply how it goes with future, it's supposed to surprise us, that's why it's such fun. And it becomes sublime when it really surprises us with something as old as pyramids.

And then the prophecy. Not only is everything converging into the mobile phone, the absolute wallet, but it is also easy to foretell that all differences between private media and public media will vanish, since any private customer (even a soldier now stuck in Iraq) can share his communications on the web and a public agency whatsoever can intercept the communications of a private customer, maybe the pictures that Abu Ghraib American soldiers - if they deserve this name - were sending to their loved ones. Moreover, anyone, public or private, have access to cinemas and television, no matter where you are and usually by using tools suitable for "private" communications as well.

Writing, as I was saying, has always existed. We have always had some papier (unless we were sans papier, of course). But today this papier is surrounding us and creates our identity, protects us to the same extent in which it inspects us. So, it happens that when some officer asks me for documents I would like to answer: "Why ask, if you know it better than I do?" Or, with a small variation, I find myself asking a question (a little disturbing and blasphemous) which can be found in Augustine's Confessions: "Why confess something to God, who knows everything?".

\section{REFERENCES (ESSENTIAL BIBLIOGRAPHY)}

Derrida, J. 1967 De la grammatologie, Paris: Ed. de Minuit.

Ferraris, M. 2005 Dove sei? Ontologia del telefonino, Milano: Bompiani.

Searle, J.R. 1995 The Construction of Social Reality, New York: The Free Press.

Smith, B. 2003 "John Searle: From speech acts to social reality", in B. Smith (ed.), John Searle, Cambridge University Press, Cambridge. 
